\title{
Palytoxin in Two Species of Xanthid Crab from the Philippines
}

\author{
Takeshi Yasumoto, Daisuke Yasumura, Yasushi OHIzumi, \\ Masami Takahashi,* Angel C. Alcala** \\ and Lawton C. Alcala** \\ Faculty of Agriculture, Tohoku University, \\ Tsutsumidori, Sendai 980, Japan \\ *Mitsubishi-Kasei Institute for Life Science, \\ 11 Minamiooya, Machida-shi, Tokyo 194, Japan \\ ** Marine Laboratory, Silliman University, \\ Dumaguete City 6501, The Philippines
}

Received July 23, 1985

\begin{abstract}
Two species of xanthid crab, Lophozozymus pictor and Demania alcalai, known to cause fatal poisoning when ingested, were collected on southern Negros, Philippines. They were highly fatal by mouse assays. The toxin in both species was identified as palytoxin,'a highly lethal toxin of zoanthids, by chromatographic and mass spectrometric analyses. The toxin was found in all tissues but the concentrations were higher in the gills, viscera, and eggs.
\end{abstract}

In tropical Pacific areas, widespread rumors exist regarding the occurrence of toxic crabs. ${ }^{1)}$ The species most frequently implicated in human poisoning is Zosimus aeneus, in which the occurrence of saxitoxin analogues ${ }^{1 \sim 4)}$ and tetrodotoxin $^{5)}$ has been confirmed. However, the toxic principle(s) in other crabs implicated in poisoning cases has remained unidentified. Teh and Gardiner first reported the presence of a potent toxin in Lophozozymus pictor and suggested the toxin to be different from both saxitoxin and tetrodotoxin on the basis of dose-death time relationships and gel permeation chromatography. ${ }^{6)}$ The incidence of a human fatality due to ingestion of this species was reported in Negros Island in Philippines by Alcala's group. ${ }^{7,8)}$ In the same area, a human fatality resulting from the ingestion of another crab, Demania toxica, also took place and a related species, Demania alcalai, was shown to be highly lethal. ${ }^{8 \sim 10)}$

We now report the isolation of a toxin from specimens of $L$. pictor and $D$. alcalai, and the identification of the toxin as palytoxin, a highly potent toxin known to occur in zoan- thids. ${ }^{11,12)}$ As a resemblance between the crab toxin and palytoxin has been suggested in pharmacological studies, emphasis was made to prove the identity of the two toxins by chromatographic and spectral evidence.

\section{MATERIALS AND METHODS}

Materials. Four specimens of Lophozozymus pictor and two specimens of Demania alcalai were collected on Negros Island, Philippines, during the period from November 1982 to May 1983. They were frozen immediately after capture and kept at $-20^{\circ} \mathrm{C}$ until used for extraction. A reference palytoxin was generously donated by Professors D. Uemura of Shizuoka University and Y. Hirata of Meijo University.

Purification. Pulverized crabs were extracted 5 times with twice the volume $(\mathrm{v} / \mathrm{w})$ of $\mathrm{MeOH}$ at room temperature, and the combined extracts were evaporated to dryness. The residue was suspended in water, freed of lipids with diethyl ether, and the toxin was extracted with $\mathrm{BuOH}$. The toxic residue obtained after evaporating the $\mathrm{BuOH}$ was successively treated on columns of TSK G3000S (Toyosoda Co., $2.8 \times 5 \mathrm{~cm}$ ), DEAE Sephadex A25 (Pharmacia Co., $2.8 \times 40 \mathrm{~cm}$ ) and CM Sephadex C-25 (Pharmacia Co., $1 \times 20 \mathrm{~cm}$ ), following the method for purification of palytoxin described by Hirata et al. ${ }^{11)}$ After re- 
peating the DEAE Sephadex and CM Sephadex chromatography, the toxin was further purified by high performance liquid chromatography (HPLC) on a Develosil ODS-10/20 column (Nomura Kagaku Co., $2 \times 25 \mathrm{~cm}$ ) with alternative use of $\mathrm{MeOH}-0.1 \mathrm{~N} \mathrm{HOAc}(8: 2)$ and MeCN- $0.05 \mathrm{~N}$ HOAc $(5: 5)$ solvents. Separation of the toxin was monitored by mouse assays and with a UVspectromonitor (Japan Spectroscopic Co., UVIDEC-100II) at $263 \mathrm{~nm}$. A comparison between the toxin and the reference palytoxin by HPLC was carried out on an ERC ODS- 1282 column (Erma Optical Works Co., $0.6 \times 25 \mathrm{~cm}$ ) with the aforementioned two solvents, as well as on a TSK G3000SW column (Toyosoda Co., $0.75 \times 60 \mathrm{~cm}$ ) using $0.03 \mathrm{~N} \mathrm{HOAc}$ as the eluant.

Thin layer chromatography (TLC). TLC was carried out on Silica gel 60 and $\mathrm{NH}_{2} \mathrm{~F}_{254} \mathrm{~S}$ plates (Merck Co.) with two different solvent systems: (A) pyridine- $\mathrm{H}_{2} \mathrm{O}-\mathrm{BuOH}-\mathrm{HOAc}(10: 12: 15: 13)$ and (B) 1 pentanol-pyridine- $\mathrm{H}_{2} \mathrm{O}(7: 7: 6)$. The toxin on the Silica gel 60 plates was detected by heating the plates after spraying with $\mathrm{H}_{2} \mathrm{SO}_{4}$, and that on the $\mathrm{NH}_{2} \mathrm{~F}_{254}$ s plates by exposure to UV light $(254 \mathrm{~nm})$.

Bioassay. A bioassay method proposed by Teh and Gardiner $^{6)}$ for the toxin in L. pictor was employed. Groups of 3 male mice of the ddY strain with body weight of $17 \mathrm{~g}$ were injected intraperitoneally with suitable volumes of sample solutions and their death times were noted. The toxin amount in mouse units (MU) was calculated from the equation $Y=225.19 X^{-0.99}$, where $Y$ and $X$ denote MU and death time in $\min$, respectively.

Spectra. UV spectra were taken in an aqueous solution with a Hitachi 124 spectrophotometer. FAB mass spectra were taken with a JMX-HX110 spectrometer using glycerol as the matrix. A cluster of cesium iodide was used to calibrate the mass scale.

\section{RESULTS}

In all the chromatographic experiments, the toxin of either $L$. pictor or $D$. alcalai was indistinguishable from palytoxin. Chromatograms of the crab toxin on columns of DEAE Sephadex and CM Sephadex were superimposable on those of palytoxin. Separation of the toxin from buffer salts was achievable on the TSK G3000S column in a similar manner to that described for palytoxin. ${ }^{11)}$ As shown in Fig. 1, the retention times for either crab toxin on an ERC ODS-1282 column and on a TSK G3000SW column were identical with those of palytoxin. The crab toxin
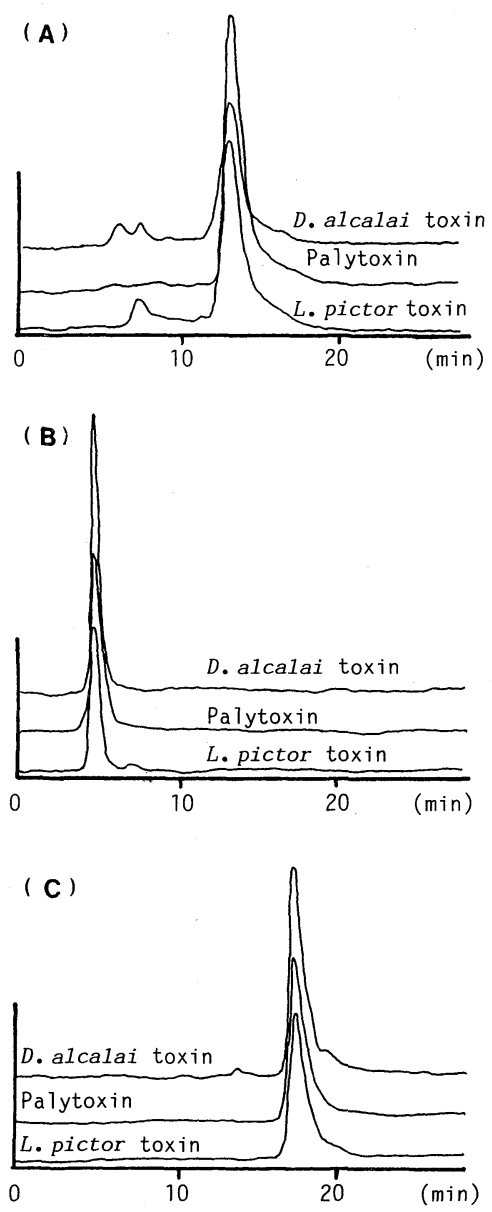

FIG. 1. Chromatograms of Crab Toxin and Palytoxin.

(A) column, ERC ODS-1282 $(0.6 \times 25 \mathrm{~cm})$; solvent, MeOH-0.1 N HOAc (8:2). (B) column, ERC ODS-1282 $(0.6 \times 25 \mathrm{~cm})$; solvent, MeOH-0.05 N HOAc $(5: 5)$. (C) column, TSK G3000SW $(0.75 \times 60 \mathrm{~cm})$; solvent $0.03 \mathrm{~N}$ HOAc. Flow rate, $0.9 \mathrm{ml} / \mathrm{min}$ for all systems; monitoring, $263 \mathrm{~nm}$.

was indistinguishable from the reference palytoxin by TLC as shown in Table I. The UV spectrum of the crab toxin was similar to that of palytoxin in having absorption maxima at 233 and $263 \mathrm{~nm}$. Molecular extinction coefficients at $263 \mathrm{~nm}$ were 23,600 for the toxin of $L$. pictor and 19,600 for the toxin of $D$. alcalai. These values are compatible with the reported value $(22,000)$ for palytoxin. $\left.{ }^{12}\right)$ The measured masses of the $\left(\mathrm{M}^{+}+\mathrm{H}\right)$ ions of the toxin of L. pictor and D. alcalai were 2680 and 2678, respectively (Fig. 2). After calibrating 
Table I. Comparison Between Crab Toxin and Palytoxin by Thin Layer Chromatography

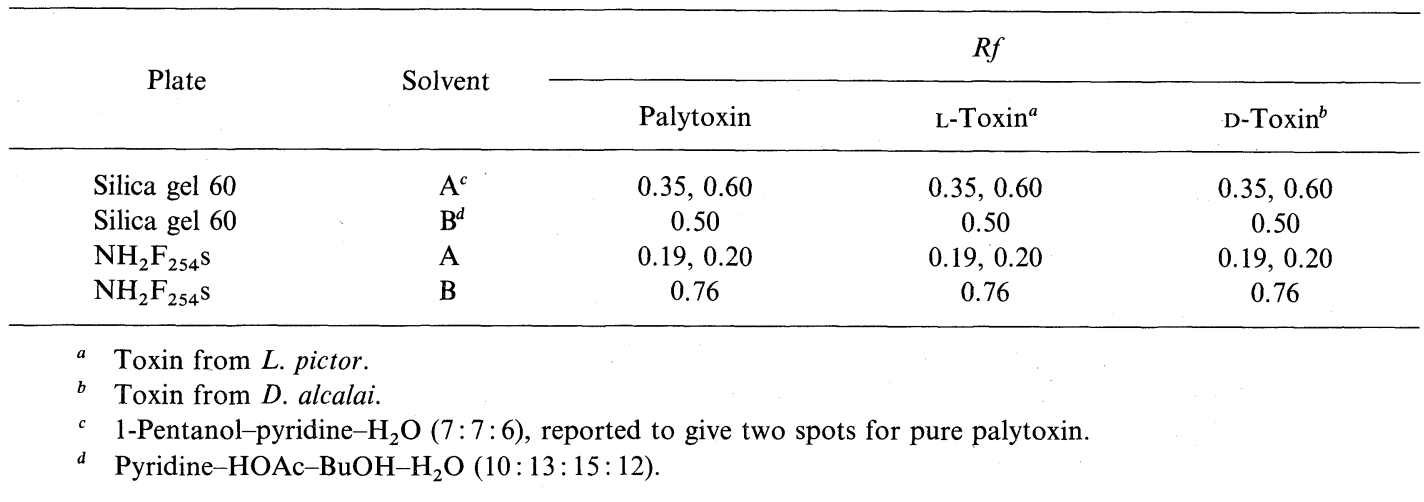

Table II. Anatomical Distribution of Palytoxin in Crabs

\begin{tabular}{|c|c|c|c|c|c|c|c|}
\hline & & \multicolumn{6}{|c|}{ Toxin levels (MU/g tissue) } \\
\hline \multicolumn{2}{|c|}{ Specimens } & \multirow{2}{*}{ Carapace } & \multicolumn{2}{|c|}{ Cheliped } & \multirow{2}{*}{ Viscera } & \multirow{2}{*}{ Gills } & \multirow{2}{*}{ Eggs } \\
\hline & & & Cuticle & Flesh & & & \\
\hline \multicolumn{8}{|c|}{ L. pictor } \\
\hline Male & $165 \mathrm{~g}$ & 2,000 & 400 & 100 & 10,000 & 2,200 & \\
\hline Male & $145 \mathrm{~g}$ & 300 & 220 & 94 & 6,000 & 2,400 & \\
\hline Female & $218 \mathrm{~g}$ & 1,400 & 170 & 50 & 6,000 & 3,000 & \\
\hline Female & $120 \mathrm{~g}$ & 160 & 40 & 20 & 200 & 180 & 700 \\
\hline \multicolumn{8}{|c|}{ D. alcalai } \\
\hline Female & $129 \mathrm{~g}$ & 500 & 400 & 240 & 4,000 & 16,000 & \\
\hline Female & $103 \mathrm{~g}$ & 500 & 160 & 80 & 5,400 & 2,400 & \\
\hline
\end{tabular}

the mass scale, the latter ion was confirmed to have a mass unit of 2679.52 , which agrees with the molecular composition of palytoxin $\mathrm{C}_{129} \mathrm{H}_{223} \mathrm{~N}_{3} \mathrm{O}_{54}, 2679.487$ daltons. Thus, all the chromatographic and spectral evidence supports that the toxin from the two species of crab was palytoxin.

The toxin contents of both crabs and the anatomical distribution of the toxin in the body are summarized in Table II. All the specimens tested were lethal. One specimen of D. alcalai contained as much as $1.2 \times 10^{6} \mathrm{MU}$ of toxin in the body. The toxin was found in all tissues and organs, but was present in higher concentration in the gills, livers and gonads. Chelipeds, especially the flesh, were low in lethal potency. The eggs of L. pictor showed the highest toxin level in the body.

\section{DISCUSSION}

The results obtained in this study confirm that the toxic principle in $L$. pictor and $D$. alcalai is palytoxin. To the best of our knowledge, the present study is the first to present evidence of the occurrence of palytoxin in crabs and to confirm its implication in human poisoning. It is not certain at present whether the toxin in the crabs is of endogenous or exogenous origin. The most plausible explanation is that the crabs accumulate the toxin by feeding on Palythoa spp., which were commonly seen in the sampling areas. However, the assumption remains to be verified in future studies, as microscopic examination of the stomach contents of the four specimens of the crab did not reveal the presence of the zoanthids. The extremely high lethal potency of the 

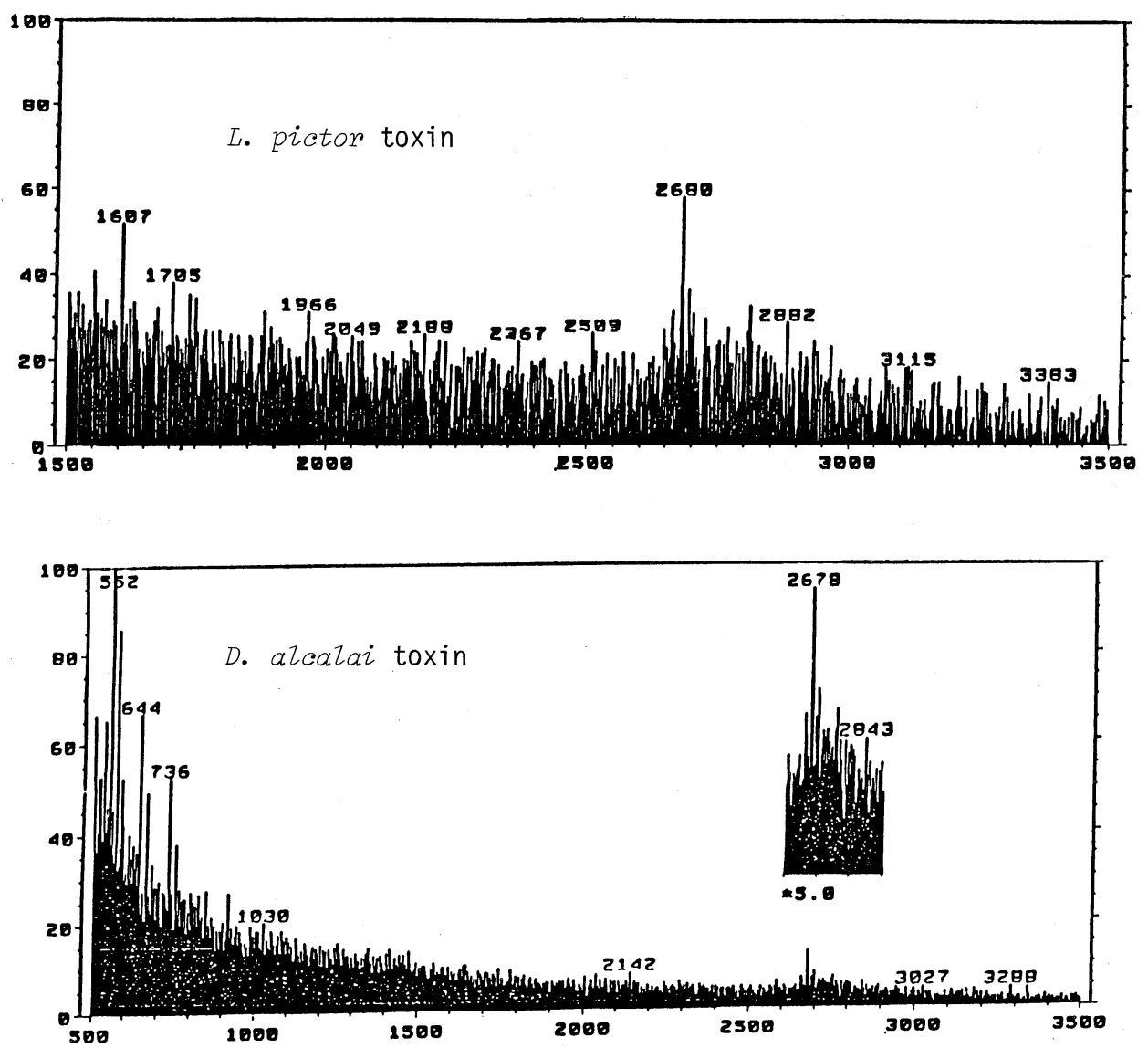

FIG. 2. FAB Mass Spectra of Crab Toxin.

Spectra were taken with a JMX HX110 spectrometer using glycerol as the matrix.

crabs is worth noting and disseminating so that the public is informed of the potential danger of the crabs. The case report on a human fatality caused by the ingestion of $D$. toxica ${ }^{9)}$ suggests that the causative toxin was also palytoxin. Effort is being exerted to obtain specimens of $D$. toxica for analysis.

Acknowledgments. The authors wish to thank Professor D. Uemura of Shizuoka University and Professor Y. Hirata of Meijo University for their gifts of the reference palytoxin and TSK G3000S gel. Thanks are also due to Drs. Y. Itagaki and I. Nojima, Application Center, JEOL Ltd., for the measurement of mass spectra. The present study was supported by a Grant-in-Aid for Scientific Research (Overseas Scientific Survey) from the Ministry of Education, Science and Culture of Japan.

\section{REFERENCES}

1) Y. Hashimoto, "Marine Toxins and Other Bioactive Metabolites" Japan Scientific Societies Press, Tokyo, 1979.

2) T. Yasumoto, Y. Oshima and T. Konta, Bull. Jpn. Soc. Sci. Fish., 47, 957 (1981).

3) K. Koyama, T. Noguchi, Y. Ueda and K. Hashimoto, Bull. Jpn. Soc. Sci. Fish., 47, 965 (1981).

4) U. Raj, H. Haq, Y. Oshima and T. Yasumoto, Toxicon, 21, 547 (1983).

5) D. Yasumura, Y. Oshima, T. Yasumoto, A. C. Alcala and L. C. Alcala, submitted to Agric. Biol. Chem.

6) Y. F. Teh and J. E. Gardiner, Toxicon, 12, 603 (1974)

7) R. B. Gonzales and A. C. Alcala, Toxicon, 15, 169 (1977).

8) A. C. Alcala, Toxicon, Suppl., 3, 1 (1983).

9) A. C. Alcala and B. W. Halstead, Clin. Toxicol., 3, 
609 (1970).

10) E. E. Carumbana, A. C. Alcala and E. P. Ortega, Silliman J., 23, 265 (1976).

11) Y. Hirata, D. Uemura, K. Ueda and S. Takano, Pure Appl. Chem., 51, 1875 (1979).
12) R. E. Moore, R. F. Dietrich, B. Hatton, T. Higa and P. J. Scheuer, J. Org. Chem., 40, 540 (1975).

13) S. Kimura and Y. Hashimoto, Publ. Seto Mar. Biol. Lab., 20, 713 (1973). 